\title{
Screening of Copper Open Metal Site MOFs for Olefin/Paraffin Separations using DFT Derived Force Fields
}

\author{
Ambarish R. Kulkarni ${ }^{1}$ and David S. Sholl ${ }^{2, *}$ \\ ${ }^{1}$ Department of Chemical Engineering, Stanford University, Stanford, CA 94305 \\ ${ }^{2}$ School of Chemical and Biomolecular Engineering, Georgia Institute of Technology, Atlanta, \\ Georgia 30332
}

*Corresponding author: E-mail: david.sholl@chbe.gatech.edu

\begin{abstract}
Keywords:
Density Functional Theory, MOFs, CuBTC, open metal sites, adsorption, force field development
\end{abstract}




\section{Overall Calculation Details}

Table S1. Comparison of the PBE-D2 optimized lattice constants for CuBTC with the experimentally reported values from Chui et al. ${ }^{1}$

\begin{tabular}{|c|c|c|}
\hline & $\begin{array}{c}\text { Experimental } \\
\text { structure }^{1}\end{array}$ & $\begin{array}{c}\text { PBE-D2 optimized } \\
\text { structure }\end{array}$ \\
\hline $\mathrm{a}=\mathrm{b}=\mathrm{c}(\AA)$ & 18.627 & 18.713 \\
\hline$\alpha=\beta=\gamma$ & $60^{\circ}$ & $60^{\circ}$ \\
\hline
\end{tabular}

Table S2. Parameters for the generic DREIDING ${ }^{2}$ force field.

\begin{tabular}{|c|c|c|}
\hline Atom Type & $\boldsymbol{\varepsilon}(\mathbf{K})$ & $\boldsymbol{\sigma}(\AA)$ \\
\hline $\mathbf{C}$ & 47.86 & 3.47 \\
\hline $\mathbf{O}$ & 48.19 & 3.03 \\
\hline $\mathbf{C u}$ & 2.52 & 3.11 \\
\hline $\mathbf{H}$ & 7.65 & 2.85 \\
\hline
\end{tabular}

Table S3. Parameters for the united atom TraPPE ${ }^{3}$ FF for alkanes and alkenes.

\begin{tabular}{|c|c|c|}
\hline Atom Type & $\boldsymbol{\varepsilon}(\mathbf{K})$ & $\boldsymbol{\sigma}(\AA)$ \\
\hline CH3_sp3 & 98 & 3.75 \\
\hline CH2_sp3 & 46 & 3.95 \\
\hline CH_sp3 & 10 & 4.65 \\
\hline CH2_sp2 & 85 & 3.675 \\
\hline CH_sp2 & 47 & 3.73 \\
\hline
\end{tabular}


Table S4. Parameters for the alkane united atom FF from Dubbeldam et al. ${ }^{4}$

\begin{tabular}{|c|c|c|}
\hline Atom Type & $\boldsymbol{\varepsilon}(\mathbf{K})$ & $\boldsymbol{\sigma}(\AA)$ \\
\hline CH3_sp3 & 98 & 3.75 \\
\hline CH2_sp3 & 46 & 3.95 \\
\hline CH_sp3 & 10 & 4.65 \\
\hline
\end{tabular}

\section{Force Field Development for Ethane and Ethylene}

Table S5. Fitted Morse parameters for the interaction of the Cu OMS with the ethane and ethylene united atoms in CuBTC.

\begin{tabular}{ccccc}
\hline $\begin{array}{c}\text { Framework } \\
\text { atom }\end{array}$ & $\begin{array}{c}\text { Adsorbate } \\
\text { united atom }\end{array}$ & $\begin{array}{c}D_{0} \\
(\mathrm{~kJ} / \mathrm{mol})\end{array}$ & $\begin{array}{c}\rho \\
(\AA)\end{array}$ & $\alpha$ \\
\hline \multirow{2}{*}{$\mathbf{C u}$} & CH3_sp3 & 1.54 & 11.93 & 3.40 \\
& CH2_sp2 & 10.46 & 8.83 & 2.64 \\
\hline
\end{tabular}



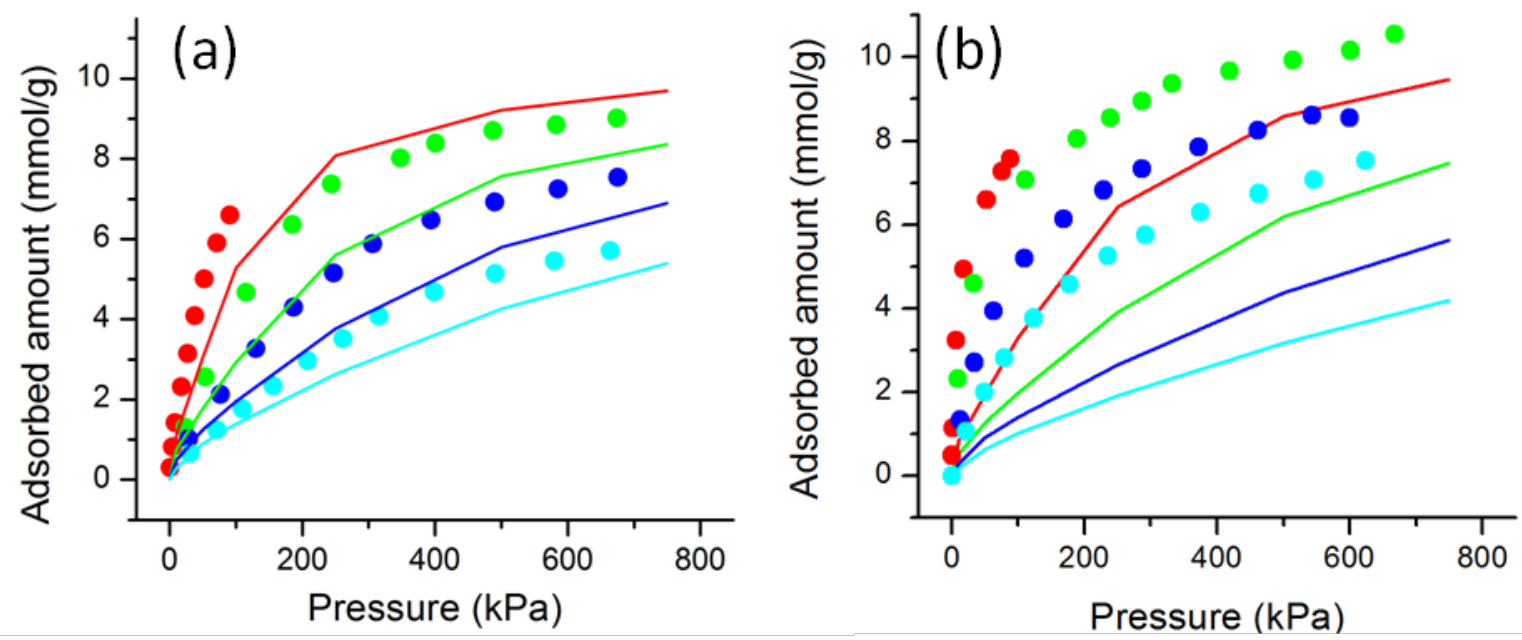

Figure S1. GCMC predicted adsorption isotherms for (a) ethane and (b) ethylene in CuBTC using the DREIDING FF for the framework atoms and the TraPPE FF (solid lines) for the adsorbates at $295 \mathrm{~K}$ (red), $323 \mathrm{~K}$ (green), $348 \mathrm{~K}$ (blue) and $373 \mathrm{~K}$ (cyan). The scaled experimental adsorption isotherms from Wang et al. ${ }^{5}$ at $295 \mathrm{~K}$ (red) and Jorge et al. ${ }^{6}$ at $323 \mathrm{~K}$ (green), $348 \mathrm{~K}$ (blue) and $373 \mathrm{~K}$ (cyan) are shown by filled circles.
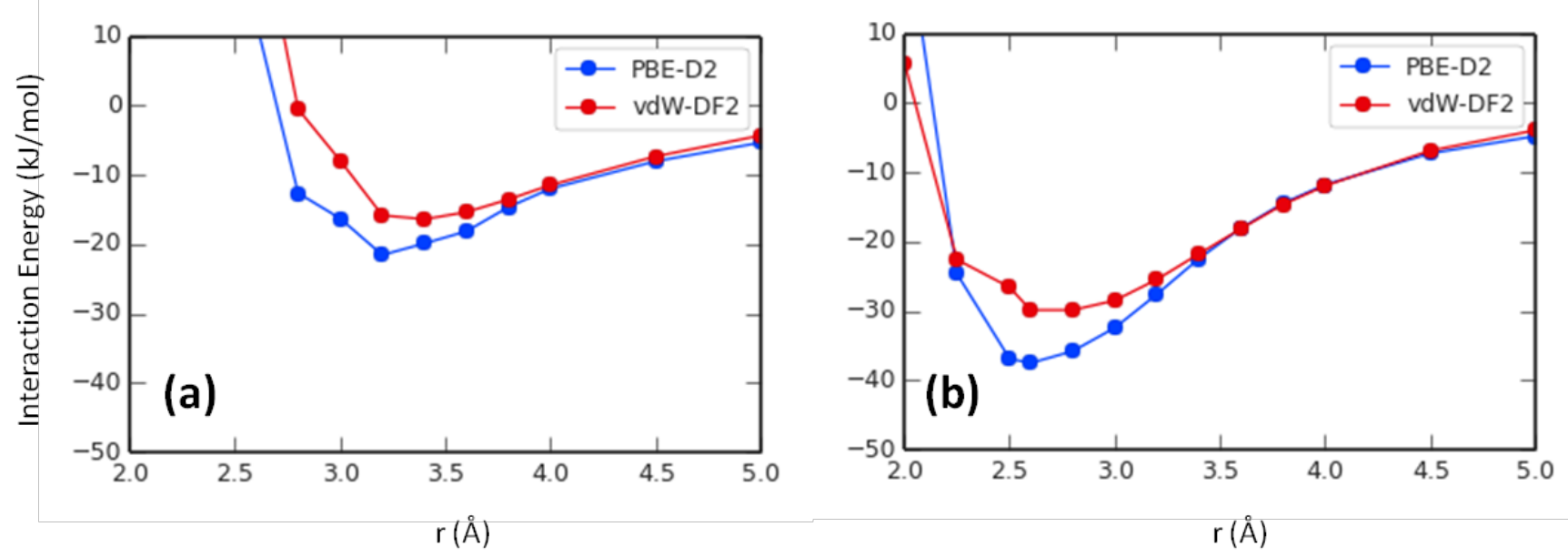

Figure S2. Interaction energies for (a) ethane and (b) ethylene in CuBTC obtained using PBED2 (blue) and vdW-DF2 (red) method. 

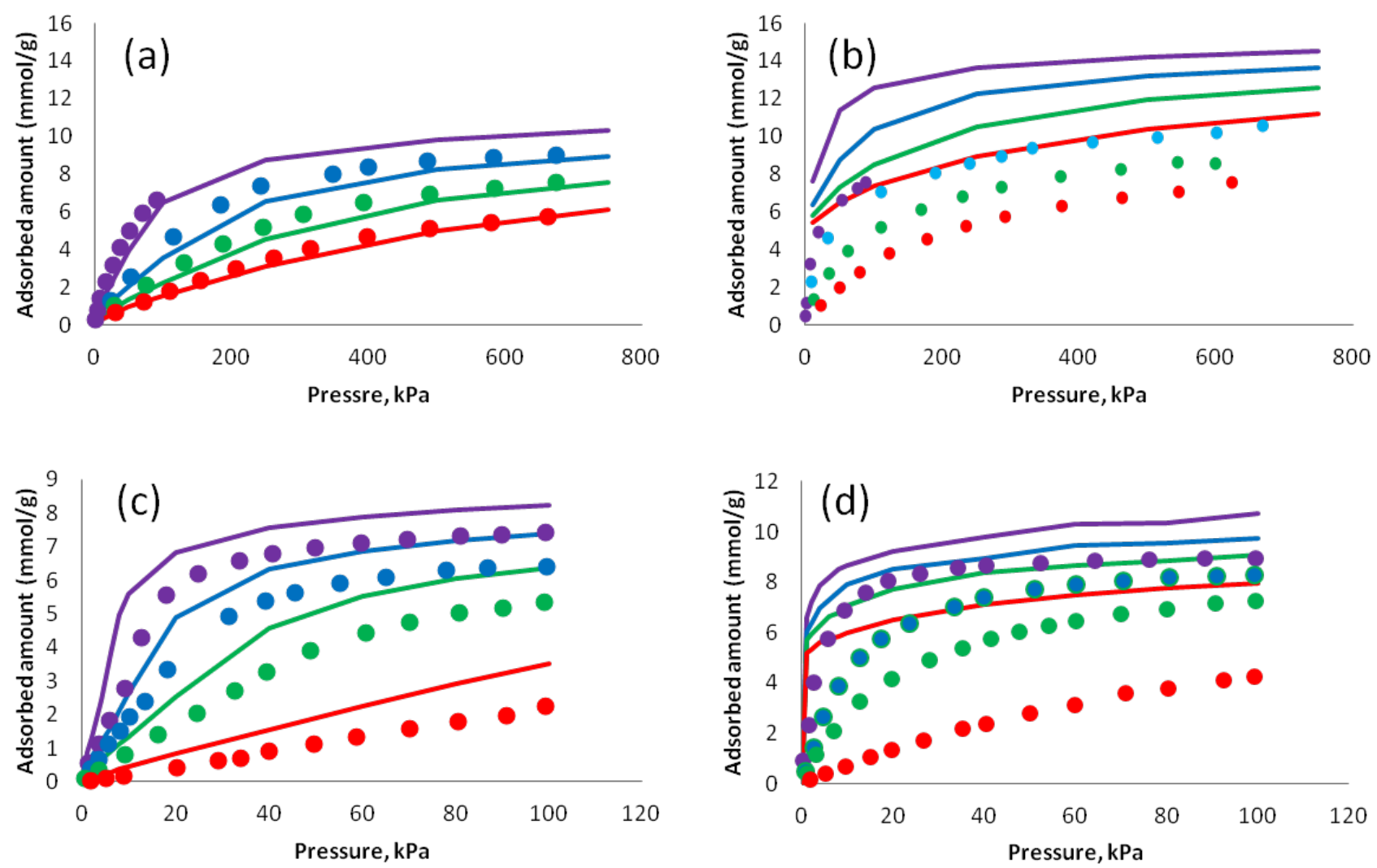

Figure S3. GCMC predicted adsorption isotherms for (a) ethane, (b) ethylene, (c) propane and (d) propylene in CuBTC using the DREIDING FF for the framework atoms and the PBE-D2 (Iteration 1) FF (solid lines) for the adsorbates at $295 \mathrm{~K}$ (purple), $323 \mathrm{~K}$ (blue), $348 \mathrm{~K}$ (green) and $373 \mathrm{~K}$ (red). 
Table S6. Constraints used for adding appropriate number of $\mathrm{H}$ atoms to the TraPPE UA model of hydrocarbons prior to all atom DFT calculations.

\begin{tabular}{|c|c|c|}
\hline Atom Type & C-H bond length $(\AA ̊)$ & Constraints \\
\hline $\begin{array}{l}\text { CH3_sp3, } \\
\text { CH2_sp2 }\end{array}$ & 1.091 & 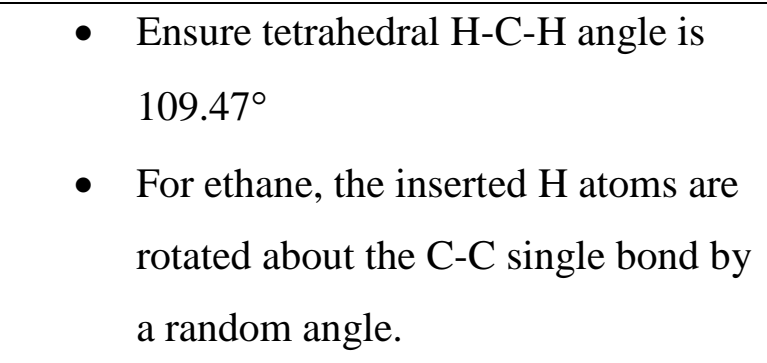 \\
\hline $\begin{array}{l}\text { CH2_sp2, } \\
\text { CH_sp2 }\end{array}$ & 1.089 & 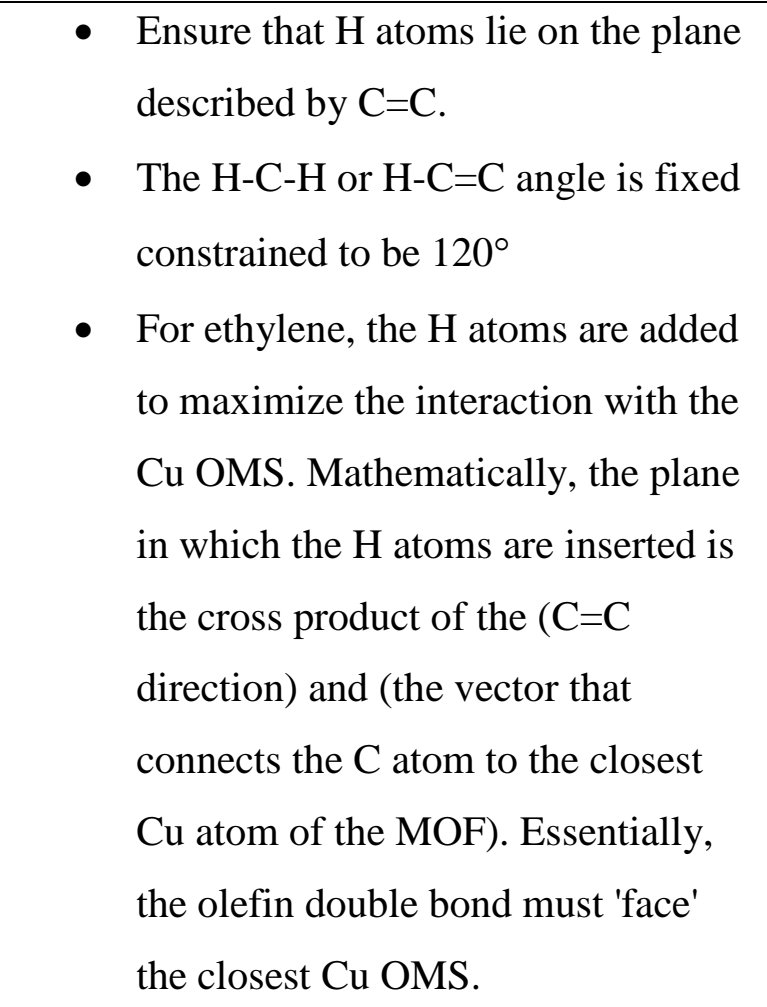 \\
\hline
\end{tabular}

Table S7. Fitted Morse parameters for the interaction of the Cu OMS with the ethane and ethylene united atoms in CuBTC for Iteration 2 force field. 


\begin{tabular}{ccccc}
\hline $\begin{array}{c}\text { Framework } \\
\text { atom }\end{array}$ & $\begin{array}{c}\text { Adsorbate } \\
\text { united atom }\end{array}$ & $\begin{array}{c}D_{0} \\
(\mathrm{~kJ} / \mathrm{mol})\end{array}$ & $\begin{array}{c}\rho \\
(\AA)\end{array}$ & $\alpha$ \\
\hline \multirow{2}{*}{$\mathbf{C u}$} & CH3_sp3 & 0.84 & 8.13 & 4.24 \\
& CH2_sp2 & 10.46 & 8.83 & 2.64 \\
\hline
\end{tabular}

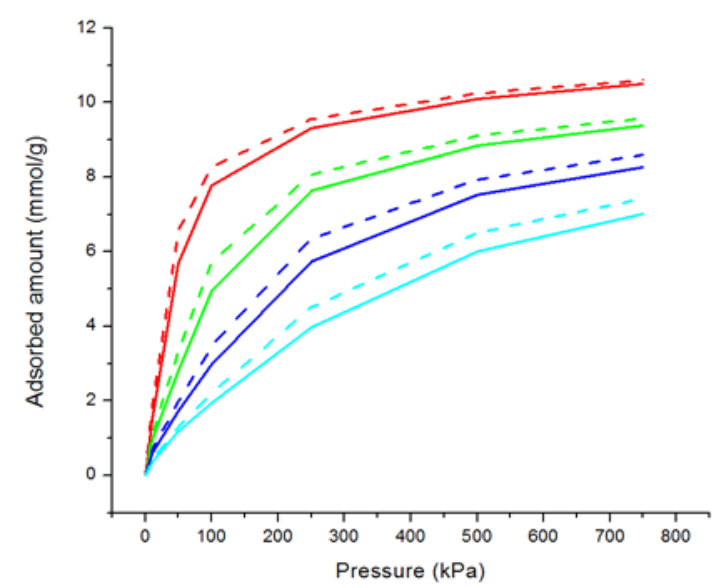

Figure S4. GCMC predicted adsorption isotherms for ethane in CuBTC using Iteration 1 (solid lines) and Iteration 2 (dashed lines) VDW-DF2 FFs at 295 K (red), 323 K (green), 348 K (blue) and $373 \mathrm{~K}$ (cyan).

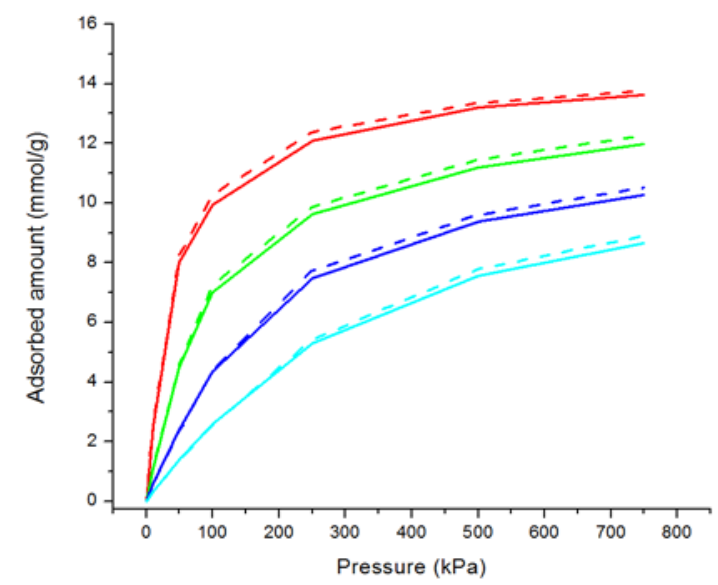

Figure S5. GCMC predicted adsorption isotherms for ethylene in CuBTC using Iteration 1 (solid 
lines) and Iteration 2 (dashed lines) VDW-DF2 FFs at $295 \mathrm{~K}$ (red), $323 \mathrm{~K}$ (green), $348 \mathrm{~K}$ (blue) and $373 \mathrm{~K}$ (cyan).

Table S8. Interaction energies for two ethylene configurations in CuBTC shown in Fig. 7 (a) and (b) calculated using vdW-DF2 and two iterations of the VDW-DF2 FF

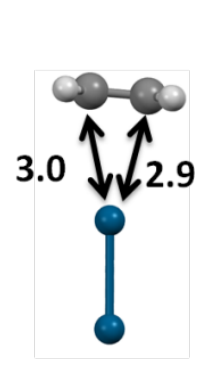

(a)

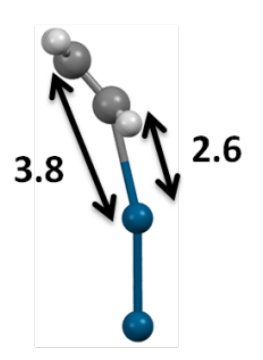

(b)

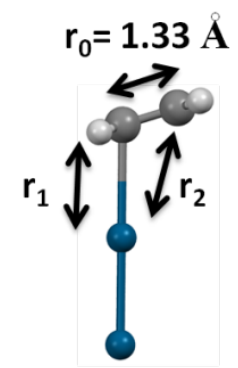

(c)

\begin{tabular}{ccc}
\hline $\begin{array}{c}\text { Interaction Energy } \\
\mathbf{( k J / m o l})\end{array}$ & Configuration (a) & Configuration (b) \\
\hline $\mathbf{v d W - D F 2}\left(E_{D F T}\right)$ & -29.1 & 9.8 \\
Iteration 1 FF & -28.9 & -17.0 \\
Iteration 2 FF & -29.1 & 8.1 \\
& $\left(E_{\text {orient }}=+0.2\right)$ & $\left(E_{\text {orient }}=+25.1\right)$ \\
\hline
\end{tabular}




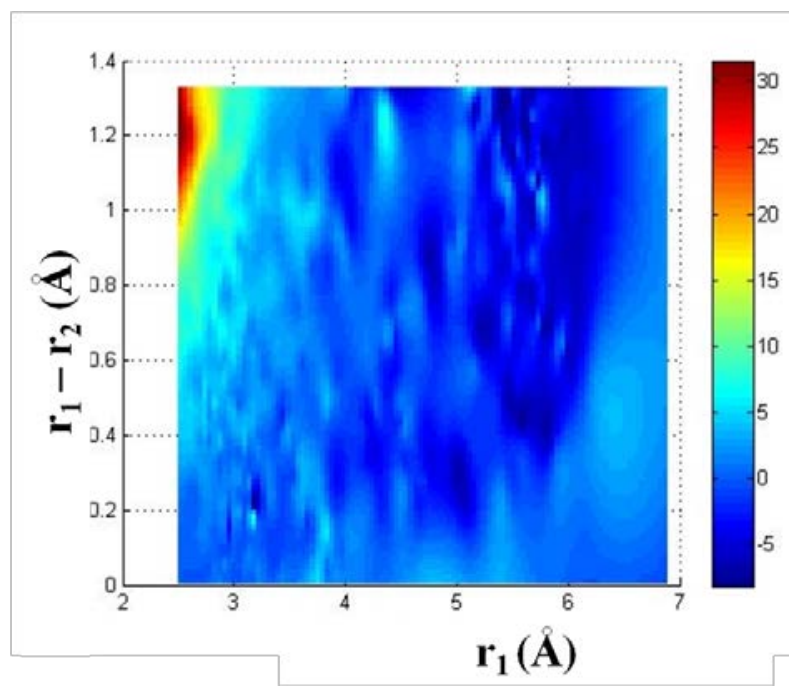

Figure S6. Surface plot indicating the correction term ( $E_{\text {orient }}$, in $\left.\mathrm{kJ} / \mathrm{mol}\right)$ required to account for the orientation of the ethylene molecule.

Table S9. Fitting parameters for the orientation dependent term, $E_{\text {orient }}$ for ethylene adsorption in CuBTC. ${ }^{\#}$

\section{A (kJ/mol) $\mathbf{B}\left(\AA^{-1}\right)$}

\begin{tabular}{lll}
\hline Ethylene & 44.4772 & 0.9803 \\
\hline
\end{tabular}

\# Morse potential parameters to be used with Iteration 2 FF are same as the Iteration 1 FF and are provided in Table 1.

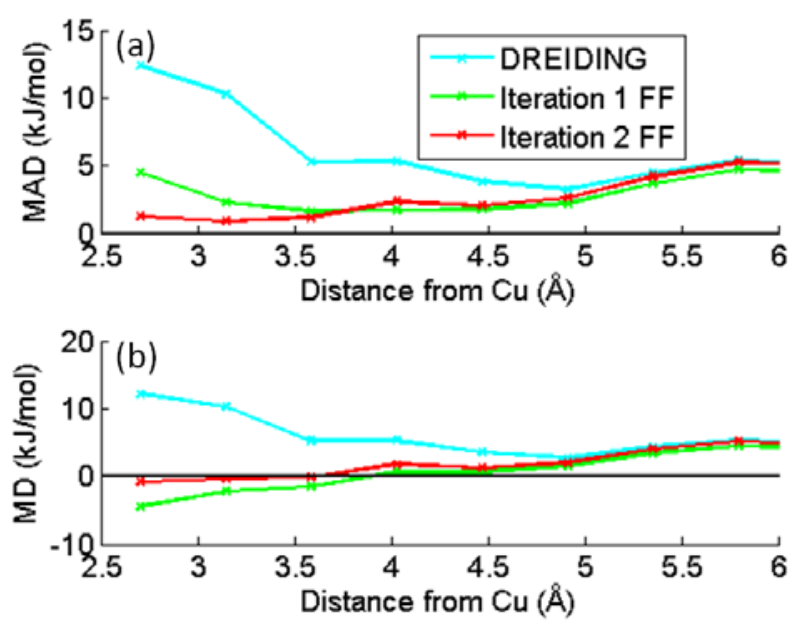


Figure S7. (a) Mean Absolute Deviation and (b) Mean Deviations as a function of distance obtained from DREIDING FF (cyan), Iteration 1 FF (green) and Iteration 2 FF (red) compared to the vdW-DF2 for 600 configurations of ethylene in CuBTC

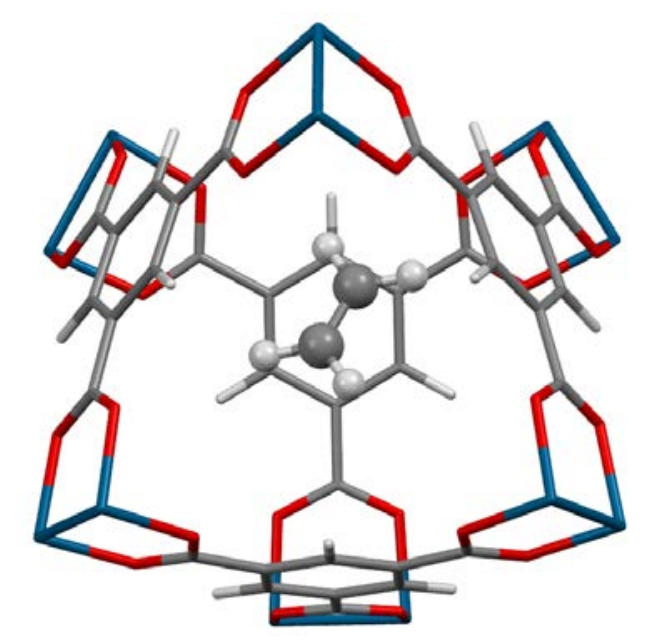

Figure S8. Example of a confined ethylene configuration within the small octahedral side pockets of CuBTC. The adsorbate is far away from Cu OMS and the strong interaction is due to the $\mathrm{C}, \mathrm{H}$ and $\mathrm{O}$ atoms. The color scheme used is $\mathrm{C}$ (grey), $\mathrm{O}$ (red), $\mathrm{H}$ (white) and Cu (blue). 

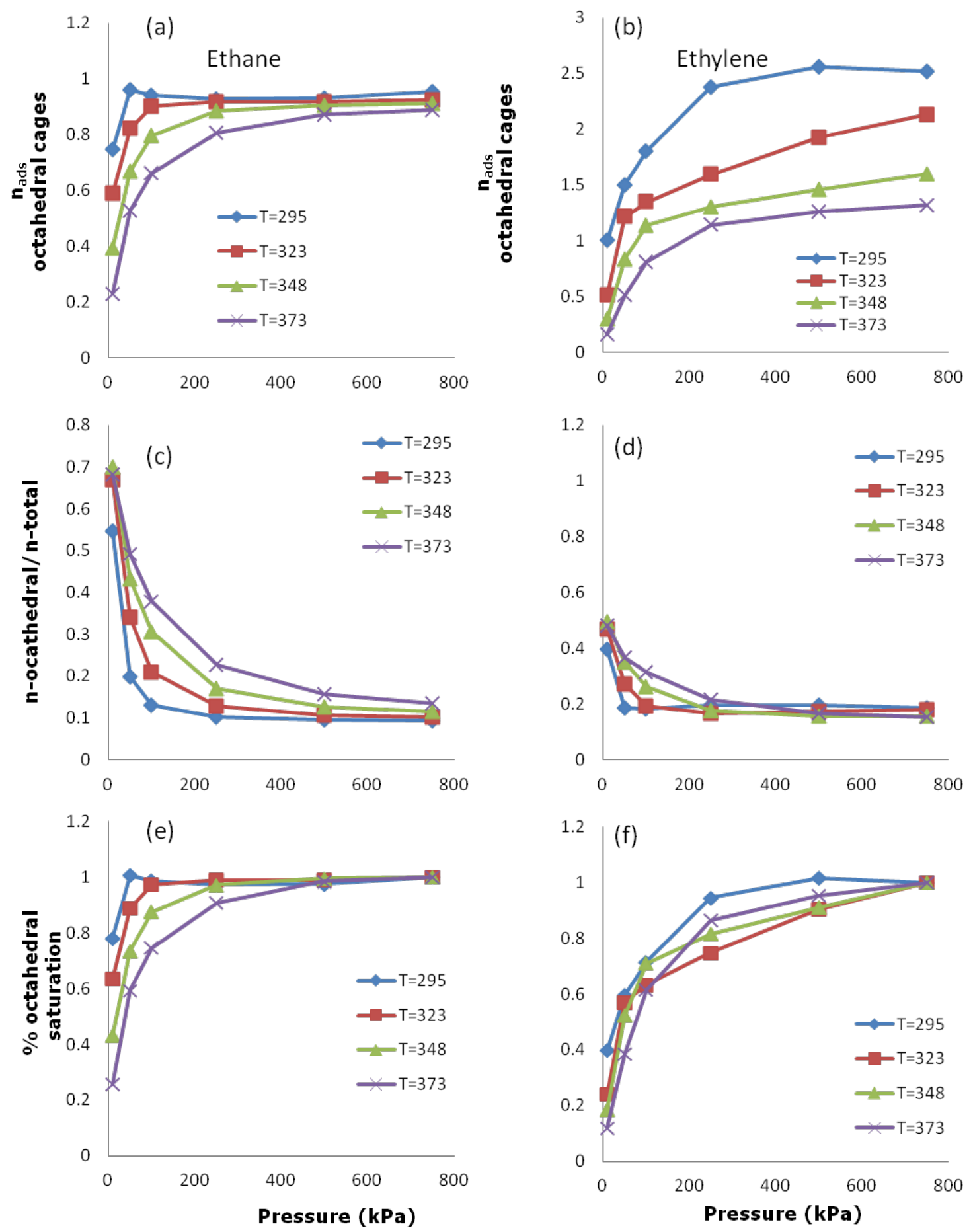

Figure S9. Number of molecules in octahedral cage (row 1), relative number of molecules in octahedral cage (row 2), \% saturation of octahedral cage for ethane (left column) and ethylene (right colum) 
- Definitions:

- $\mathrm{n}_{\mathrm{ads}}$ octahedral cages $=\mathrm{n}_{\mathrm{ads}}$, octahedral

$-\mathrm{n}_{\mathrm{ads}, \text { octahedral }}=\mathrm{n}_{\mathrm{ads}, \text { total }}-\mathrm{n}_{\mathrm{ads}}$, blocked-octahedral-pockets

- $\mathrm{n}_{\text {ads,total }}=$ Adsorbed amount for isotherm obtained for a CuBTC

- $\mathrm{n}_{\text {ads-blocked-octahedral-pockets }}=$ Adsorbed amount for isotherm obtained for a CuBTC with blocked pockets such that insertions are not allowed in the pockets during GCMC

- Using the above terms, the number of ethane and ethylene molecules in the octahedral cages was calculated (Fig S9 (a) and (b)). Notice that the saturation limit (max molecules in octahedral cage) depends on the temperature.

- Using the saturation limit at each temperature, the \% saturation of each cage was estimated as a function of pressure (Fig S9 (e) and (f)). For ethane, even on the VDWDF2 FF interaction energy ( $-35 \mathrm{~kJ} / \mathrm{mol}$ ), the octahedral cage is saturated at $\sim 100 \mathrm{kPa}$. For ethylene, the cage is $\sim 80 \%$ saturated at $100 \mathrm{kPa}$. However, the correct value is given by vdW-DF2 DFT energy $(-40 \mathrm{~kJ} / \mathrm{mol})$ which implies that the octahedral cage should be saturate at lower pressures. However, since the difference in relative energies is $\sim 5$ $\mathrm{kJ} / \mathrm{mol}$ AND even at $100 \mathrm{kPa}$, the octahedral cage only accounts for 20 - $40 \%$ of the total adsorbed amount, our VDW-DF2 FF isotherms should be relatively accurate.

- Overall, the contribution of the differences between VDW-DF2 FF and vdW-DF2 DFT are negligible above $\sim 100 \mathrm{kPa}$.

- More accurate treatment is possible by artificially increasing hte energy of the adsorbates in the octahedral cages by $5 \mathrm{~kJ} / \mathrm{mol}$.

- As the propylene binding is larger and the saturation capacity is lower, this effect is less important for propylene.

- Further for other MOFs that do not have the octahedral cages, this underestimation by VDW-DF2 FF does not occur. 


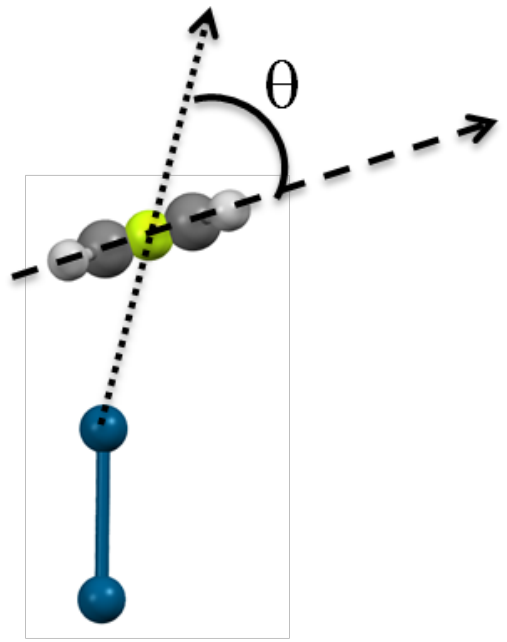

Figure S10. The angle, $\theta$ formed between the double bond of the ethylene molecule (dashed line) and the vector from the nearest $\mathrm{Cu}$ atom to the $\mathrm{COM}$ (dotted line). The color scheme used is $\mathrm{C}$ (grey), $\mathrm{O}$ (red), $\mathrm{H}$ (white) and $\mathrm{Cu}$ (blue). The center of mass (COM) of ethylene is represented by the yellow atom.
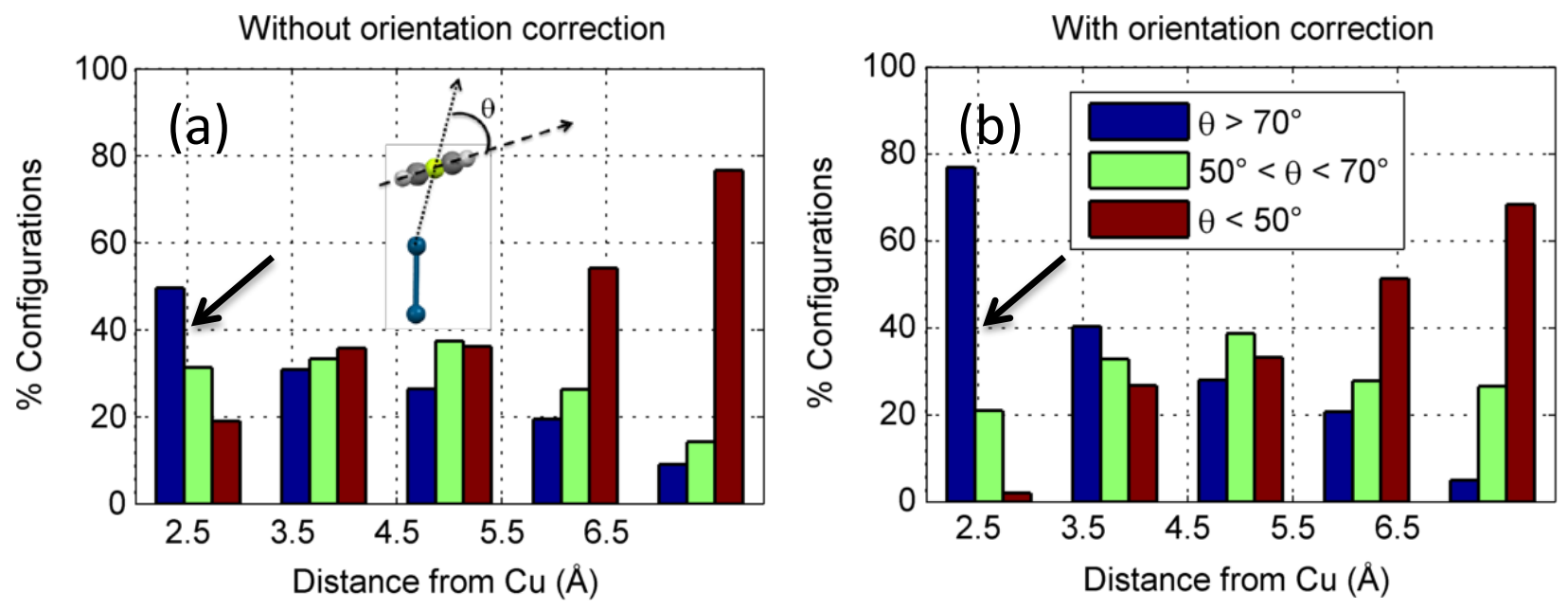

Figure S11. Angle ( $\theta$ ) formed between the double bond of the ethylene molecule and the vector from the nearest $\mathrm{Cu}$ atom to the $\mathrm{COM}$ of ethylene (yellow atom) as a function of distance. 


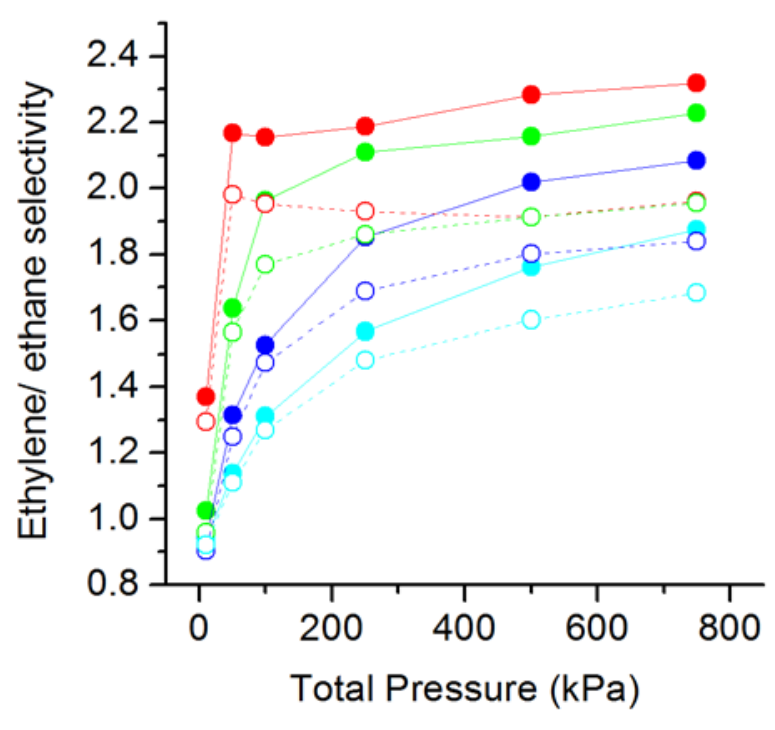

Figure S12. Selectivity calculated from GCMC simulations of equimolar ethylene/ethane mixtures in CuBTC using the Iteration 1 (empty circles) and Iteration 2 (filled circles) of the VDW-DF2 FF at $295 \mathrm{~K}$ (red), $323 \mathrm{~K}$ (green), $348 \mathrm{~K}$ (blue) and $373 \mathrm{~K}$ (cyan).

To investigate the effect of the including the orientation dependent term, we simulated the adsorption of an equimolar mixture of ethylene and ethane in CuBTC at various pressure and temperatures (Fig. S12). We see that the Iteration $2 \mathrm{FF}$ always predicts slightly higher ethylene/ ethane selectivity than the Iteration $1 \mathrm{FF}$. These results indicate that including the orientation dependent term affects the configurations of the olefins in an important way and should be included during the GCMC simulations of olefins. From Figure S12, at low pressures the ethylene/ethane selectivity is close to 1 , as the adsorption preferentially occurs in the nonselective octahedral cages. As the pressure is increased, the selectivity calculated from Iteration 2 FF increases to 2.3 (1.9) at $295 \mathrm{~K}$ (373 K). Comparing the two iterations of the FF, we see that the Iteration $2 \mathrm{FF}$ always predicts a slightly higher ethylene/ ethane selectivity than the Iteration $1 \mathrm{FF}$. 


\section{Force Field Development for Propane and Propylene}

In the main text, we have outlined our force field development algorithm for ethane and ethylene adsorption in CuBTC using periodic DFT single point energy calculations. We now turn to systematically extending the same approach for higher hydrocarbons such as propane and propylene.

We now have Morse FF parameters for CH2_sp2 UA (ethylene) and CH3_sp2 UA (ethane) interactions with the $\mathrm{Cu}$ OMS. To describe adsorption of propane and propylene, additional CH_sp2 (propylene) and CH2_sp2 (propane) interaction parameters are required. The steps involved in this calculation are similar to the previous Section and only a brief description of the method ${ }^{7}$ is provided here.

Using a similar strategy as before, we performed single point energy calculations for an initial set of favorable configurations of propane and propylene in CuBTC. The propylene molecule is appropriately oriented to maximize the interaction of the $\mathrm{C}=\mathrm{C}$ double bond with the $\mathrm{Cu}$ OMS. The vdW-DF2 functional is used to obtain the interaction energies from periodic DFT calculations and the results are shown in Figure S13.

Of the initial configurations sampled in our work, the largest interaction energy (-38.0 $\mathrm{kJ} / \mathrm{mol}$ ) is seen for propylene at a distance of $2.8 \AA$ from the Cu OMS. This is comparable to ethylene results $(-29.8 \mathrm{~kJ} / \mathrm{mol}$ at $2.8 \AA)$, indicating that the pi-bond/Cu OMS interactions are similar in both the olefins. For propane, the strongest interaction $(-22.3 \mathrm{~kJ} / \mathrm{mol})$ is seen at a larger distance of $3.4 \AA$ as specific interactions with the $\mathrm{Cu}$ atoms are absent.

The contribution of the unknown CH_sp2 (for propylene) and CH2_sp3 (for propane) interactions with the $\mathrm{Cu}$ atom are obtained by subtracting the known components from the total vdW-DF2 interaction energy (dotted lines, Fig. S13). These known terms include the CH2_sp2/Cu (from ethylene), CH3_sp2/Cu (from ethane) and DREIDING FF for C, $\mathrm{H}$ and $\mathrm{O}$ interactions. 


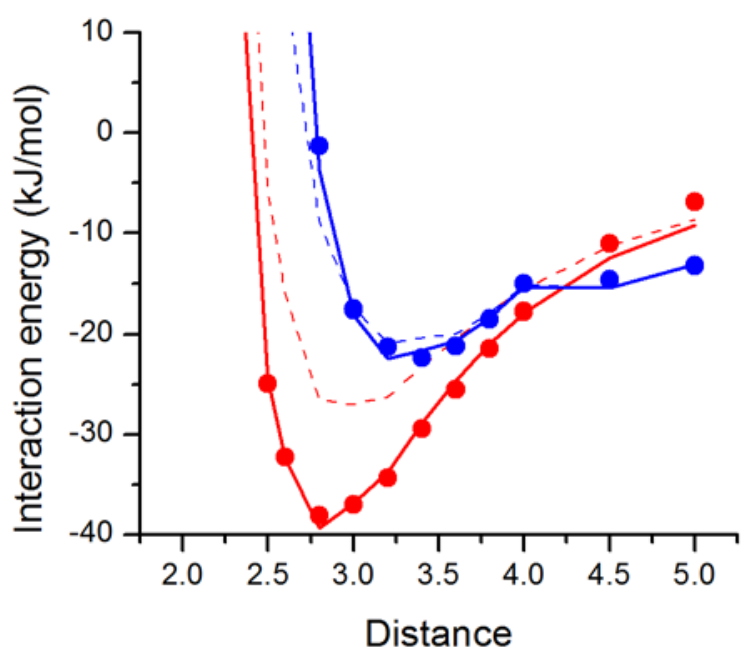

Figure S13. Interaction energies for initial configurations of propane (blue) and propyelne (red) in CuBTC calculated using vdW-DF2 DFT method (filled circles) and the fitted force field (solid lines). The dotted lines represent the contributions from the known CH2_sp2 and CH3_sp3 interations with the framework.

Table S10. Fitted Morse parameters and orientation dependent terms for the interaction of the Cu OMS for propylene and propane in CuBTC.

\begin{tabular}{cccccc}
\hline $\begin{array}{c}\text { Adsorbate } \\
\text { united atom }\end{array}$ & $\begin{array}{c}D_{0} \\
(\mathrm{~kJ} / \mathrm{mol})\end{array}$ & $\begin{array}{c}\rho \\
(\AA)\end{array}$ & $\alpha$ & $\begin{array}{c}\text { A } \\
(\mathrm{kJ} / \mathrm{mol})\end{array}$ & $\begin{array}{c}\text { B } \\
\left(\AA^{-1}\right)\end{array}$ \\
\hline CH2_sp3 & 1.38 & 19.14 & 3.34 & - & - \\
CH_sp2 & 24.9 & 6.7 & 2.11 & 9.3957 & 0.5106 \\
\hline
\end{tabular}

The difference between the vdW-DF2 and the known components is calculated and is fit using a classical Morse potential to give required parameters for the $\mathrm{CH} \_s p 2 / \mathrm{Cu}$ (for propylene) and $\mathrm{CH} 2 \_s p 3 / \mathrm{Cu}$ (for propane) interactions. The results shown in Figure S13 indicate that the fitted Morse potential gives good agreement with the vdW-DF2 interaction energies. This FF is denoted as VDW-DF2 (Iteration 1). Note that the our vdW-DF2 binding energy for propylene ($40 \mathrm{~kJ} / \mathrm{mol})$ are in better agreement with benchmark CCSD(T)/CBS predictions ${ }^{8}(-41 \mathrm{~kJ} / \mathrm{mol})$ than 
the previously used PBE approach ${ }^{6}(-33 \mathrm{~kJ} / \mathrm{mol})$. Further details are given in the Supporting Information.

Similar to the previous calculations for ethylene and ethane, another iteration is performed using 400 GCMC generated configurations of propane and propylene in CuBTC. The final FF parameters for the Iteration $2 \mathrm{FF}$ include the orientation dependent term for propylene and are shown in Table S10. Figure S14 compares the vdW-DF2 predicted energies for 400 propylene configurations with the VDW-DF2 (Iteration 2) FF. The MAD (MD) is reduced from $4.0 \mathrm{~kJ} / \mathrm{mol}$ (2.7 $\mathrm{kJ} / \mathrm{mol})$ for Iteration 1 to $3.5 \mathrm{~kJ} / \mathrm{mol}(0.1 \mathrm{~kJ} / \mathrm{mol})$ for Iteration 2 when the orientation dependent term is included. Compared to the MAD for ethylene ( $\sim 2 \mathrm{~kJ} / \mathrm{mol})$, the slightly higher MAD for propylene is due to the increasing complexity of the adsorbate and the addition degree of freedom from the CH3_sp3 united atom.

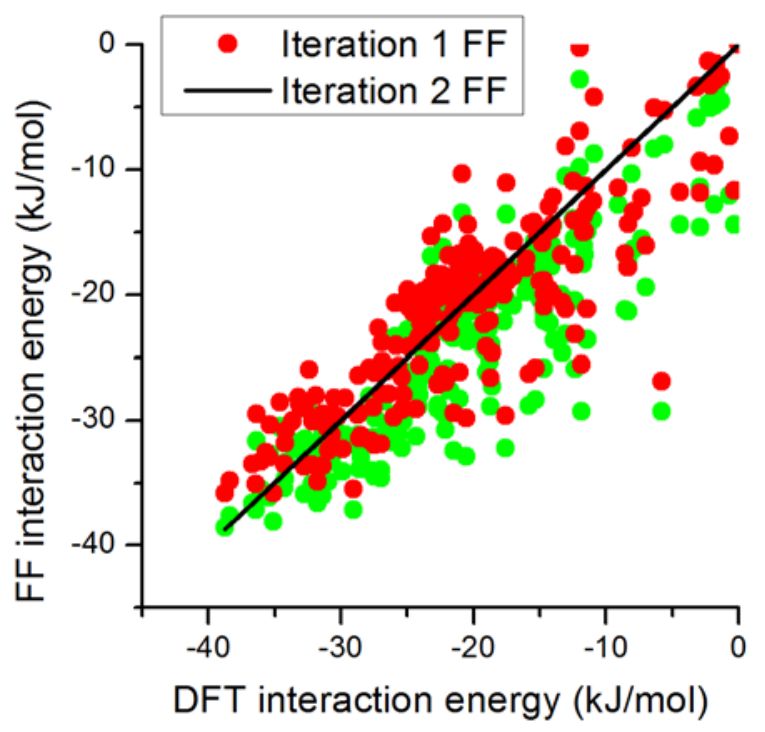

Figure S14. Comparison of the interaction energies calculated from vdW-DF2 DFT method with the VDW-DF2 (Iteration 1) FF (green) and VDW-DF2 (Iteration 2) FF (red) for 400 configuration of propylene in CuBTC. 


\section{Transferability to other MOFS}

Table S11. Experimentally measured (from He et al..$^{9}$ ) and calculated surface areas for MOFs containing $\mathrm{Cu}$ OMS

\begin{tabular}{|c|c|c|c|c|c|}
\hline \multicolumn{3}{|c|}{ Common } & \multirow{2}{*}{$\begin{array}{c}\text { Expt SA } \\
\left(\mathrm{m}^{2} / \mathrm{g}\right)\end{array}$} & \multirow{2}{*}{$\begin{array}{c}\text { Expt PV } \\
\text { (cc/g) }\end{array}$} & \multirow{2}{*}{$\begin{array}{c}\text { Calculated PV } \\
\text { (cc/g) }\end{array}$} \\
\hline Index & Name & REFCODE & & & \\
\hline 1 & CuBTC & DOTSOV & 2139.1 & 0.76 & 0.85 \\
\hline 2 & MOF-505 & LASYOU & 1703.7 & 0.61 & 0.79 \\
\hline 3 & PCN-16 & NUTQEZ & 2809.7 & 1.0 & 1.00 \\
\hline 4 & UMCM-150 & PIVBEC & 3330.4 & 1.21 & 1.25 \\
\hline 5 & NOTT-101 & CESFOW & 2929.8 & 1.05 & 1.16 \\
\hline 6 & NOTT-102 & CESFIQ & 3590.1 & 1.3 & 1.39 \\
\hline 7 & UTSA-20 & ONIXOZ & 1894.1 & 0.67 & 0.77 \\
\hline
\end{tabular}

Figure S15. Predicted Ethane and Ethylene isotherms for MOF-505, PCN-16, UMCM-150, NOTT-101, NOTT-102 and USTA-20 at 273 (dotted lines) and $296 \mathrm{~K}$ (solid lines) using the DREIDING FF (blue) and VDW-DF2 FF (red). The scaled experimental data from He et al. ${ }^{9}$ is shown by the black symbols.
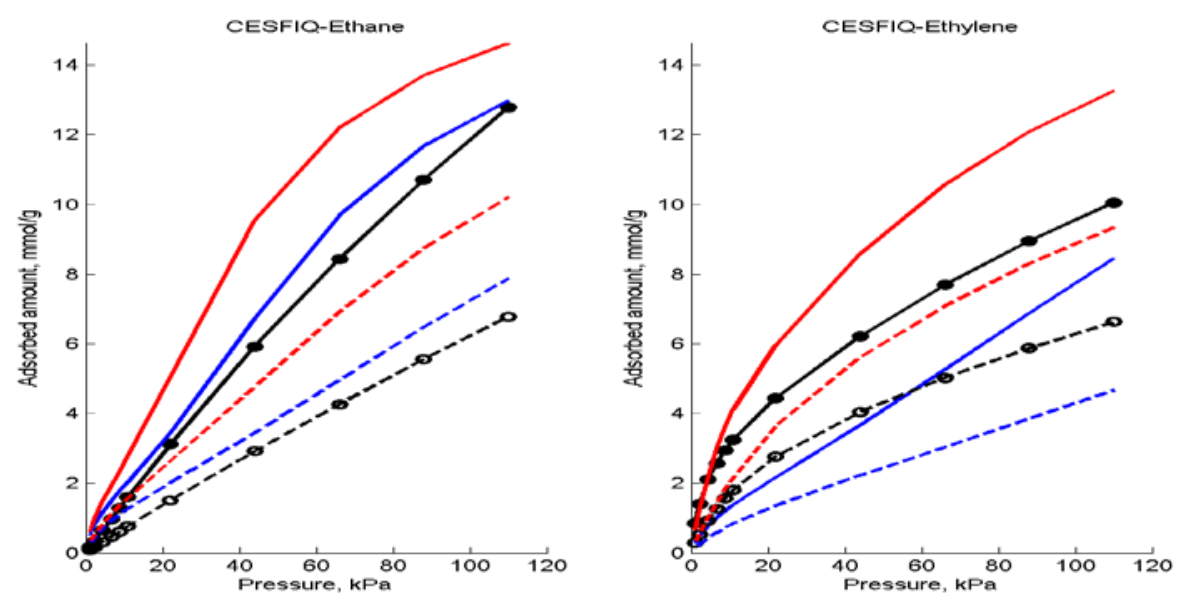

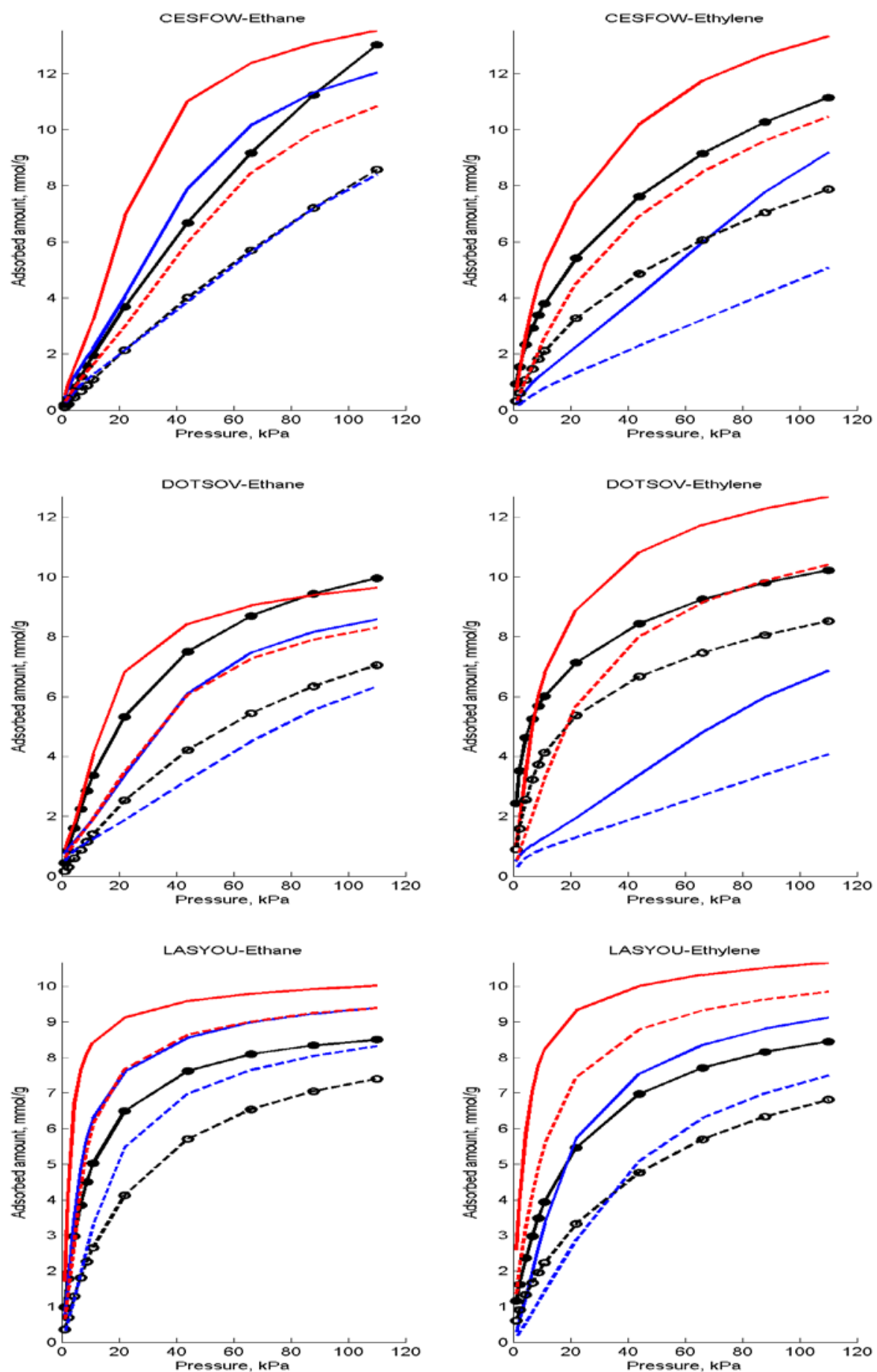

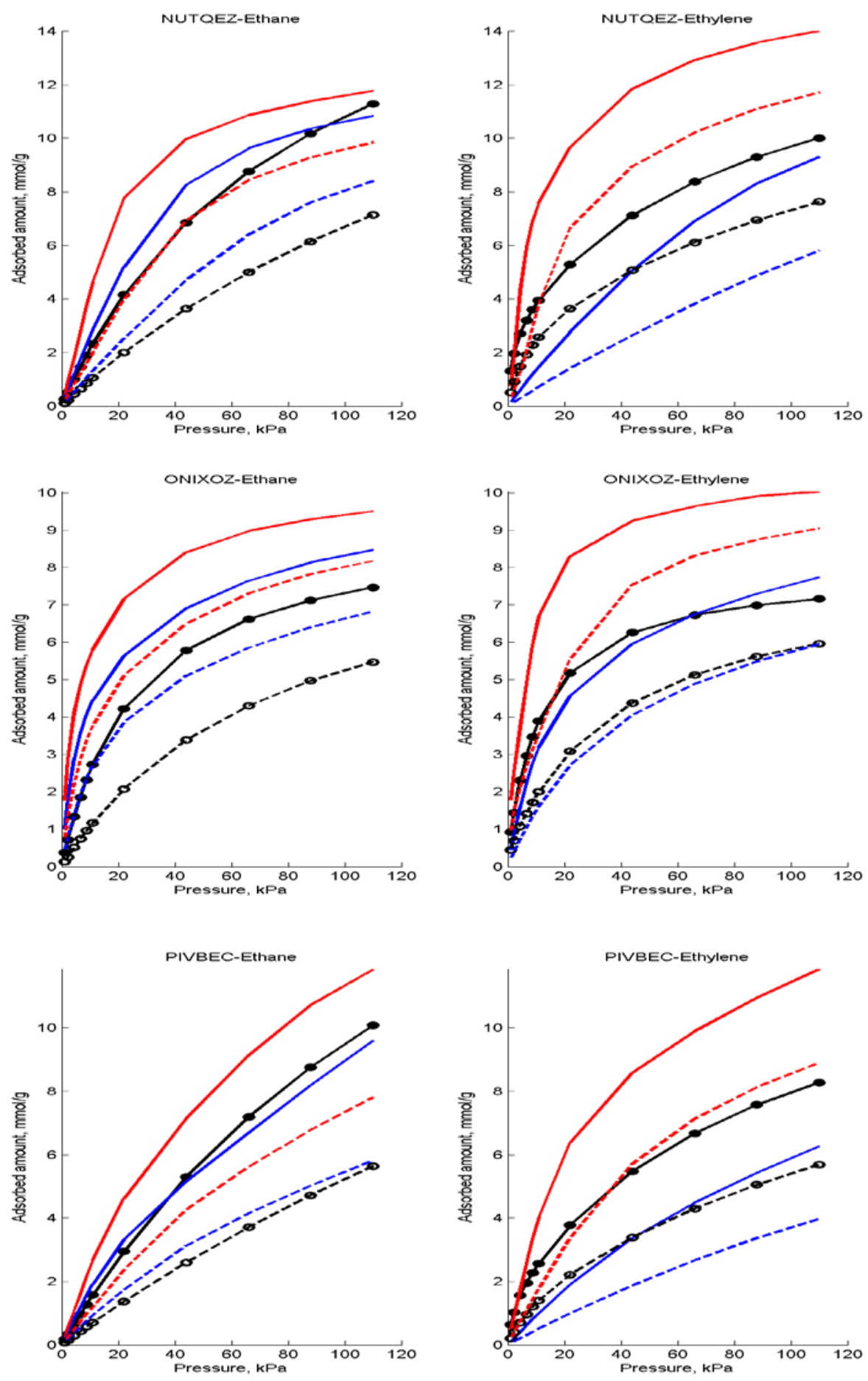
Table S12. Reasons for differences in the scaled experimental isotherms and the VDW-DF2 predicted isotherm for data reported by He et al. ${ }^{9}$

1. DRIEDING-FF for Ethylene and Ethane: In many cases (ONIXOZ,NUTQEZ, LASYOU), the calculated isotherm for DRIEDING FF for ethylene agrees well with the experimental data. Given that the DRIEDING FF fails at predicting olefin/OMS interaction, it seems likely that the only a small fraction of open metal sites are available for adsorption of olefins. This is further evidenced by higher or comparable ethane adsorption in all materials.

As many of the MOFs were activated only at $100-120^{\circ} \mathrm{C}$, it is likely that complete removal of water from the Cu-OMS was not achieved. Thus, the disagreement between the predicted isotherms and the low-temperature, low-pressure experimental isotherms is likley due to incomple availibitiy of $\mathrm{Cu}$-open metal sites.

2. Experimental PV: The experimental and calculated PVs are in reasonable agreement. However, it is not clear if all the Cu OMS of the structure are available for adsorption.

3. Adsorption temperature: The experimental adsorption isotherms are reported at tempeature of $273 \mathrm{~K}$ and $296 \mathrm{~K}$ for ethane and ethylene adsorption. At these low temperatures, it is unclear if equilibrium has been achieved as we also observe systematic over estimation of the experimental isotherms at $273 \mathrm{~K}$ for CuBTC MOF. For the higher temperatures, we observe excellent agreement with other experimental reports for CuBTC..$^{10-11}$

4. Small pressure range: The pressure range used for the adsorption experiments is only upto 1.2 bar. This is a small range compared to the experiments of Jorge et al. ${ }^{12}$ that report uptake at 8 bar for CuBTC. As our prediction is consistent with the intermediate and high pressure data of Jorge et al. for CuBTC, comparision of our predictions to expeirmentla data that spans a larger pressure range is necessary. 

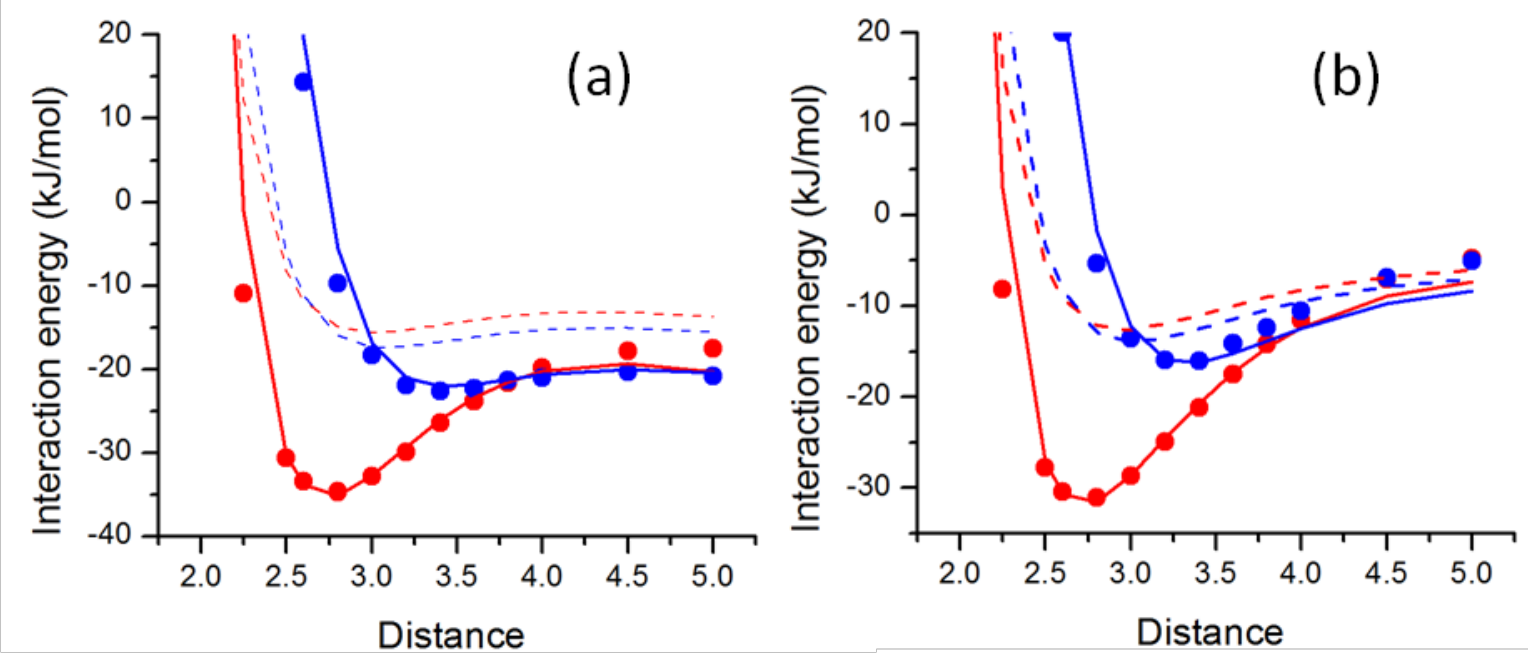

Figure S16. Interaction energies for initial configurations of ethane (blue) and ethylene (red) in (a) MOF-505 and (b) PCN-16 calculated using vdW-DF2 DFT method (filled circles) and the VDW-DF2 (Iteration 2) force field (solid lines). The dotted lines represent the contributions from the generic DREIDING FF for $\mathrm{C}, \mathrm{H}$ and $\mathrm{O}$ interactions.
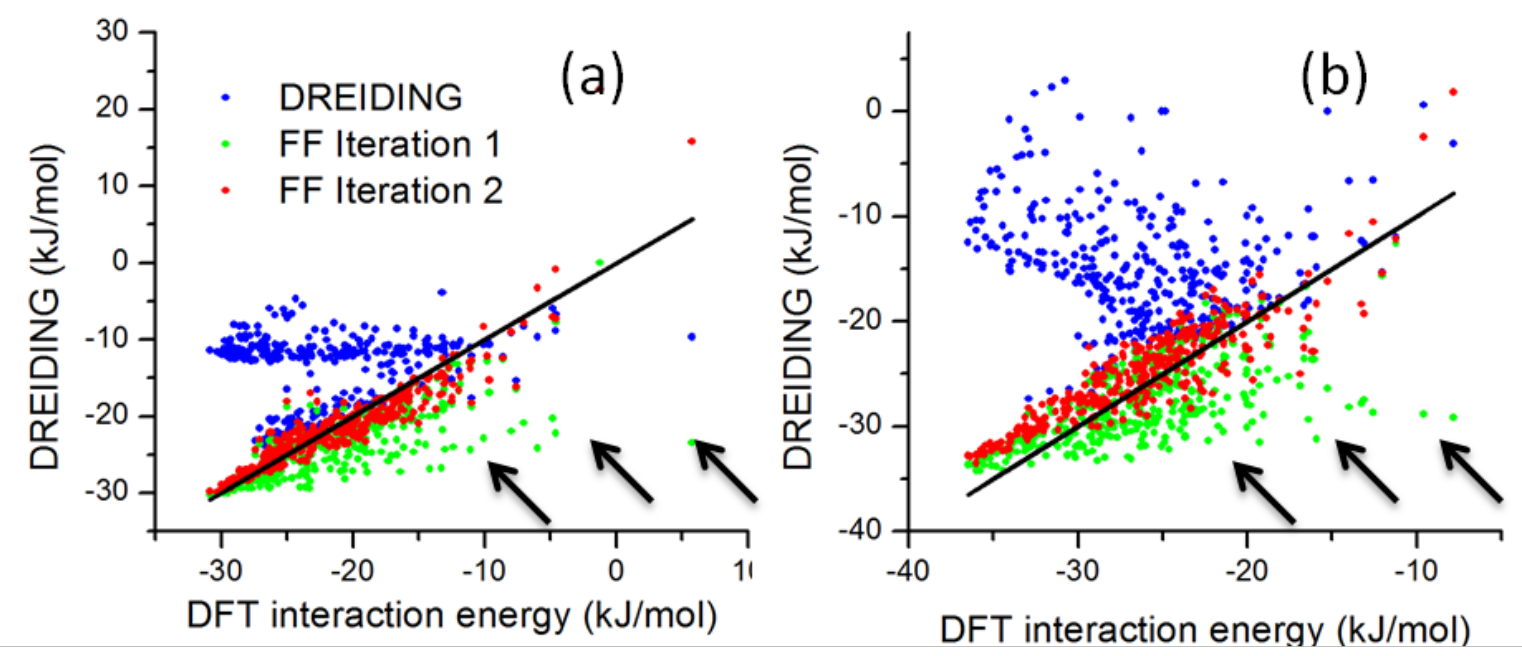

Figure S17. Interaction energies for 400 GCMC configurations of ethylene in (a) MOF-505 and

(b) PCN-16 calculated using vdW-DF2 DFT method compared to the predictions form DREIDING FF (blue), VDW-DF2 (Iteration 1) FF (green) and the VDW-DF2 (Iteration 2) FF (red). 
Table S13. Summary of the algorithm used for automatically identifying $\mathrm{Cu}$ open metal site MOFs from the CoRE MOF database. ${ }^{13}$

\section{Steps Comments}

1. Determine the connectivity matrix for a given MOF. Ensure that no isolated clusters (free solvent) are present.

2. Based on the connectivity analysis, identify unique cluster types for each metal center. Constraint: Only MOFs with Cu cluster are considered

3. Identify $\mathrm{Cu}$ clusters that are consisting of $\mathrm{Cu}$ atoms bonded to 5 other atoms. Ensure that the metal center geometry is octahedral with one axial bond missing.

4. Constraint: Restrict the search only to MOFs that contain $\mathrm{Cu}-\mathrm{Cu}$ bond in the axial position of the $\mathrm{Cu}$ metal center.

5. Visually confirm that the open metal site is similar to the $\mathrm{Cu}-\mathrm{Cu}$ dimer in $\mathrm{CuBTC}$.

6. Verify that the $\mathrm{Cu}$ OMS is accessible to adsorbates and is connected to the main channel of the MOF. 
Table S14. CSD refcodes for the 94 MOFs containing the di-copper metal cluster identified using the algorithm in Section 6 of the main text.

\begin{tabular}{|l|l|l|l|l|}
\hline ACUFEK & EPOTAF & LEVDIB & PARNIH & XAHPAZ \\
\hline ADASIJ & FEBXIV & LURRIA & PARNON & XAHPED \\
\hline ALAMUW & FECXES & LUYHAP & PEWLUA & XAHPIH \\
\hline ANOMUM & FIQCEN & MAFJIO & QOJVAM & XAHPON \\
\hline ANUGEW & GAGZEV & MEHMET & QOWRAVO1 & XAHPUT \\
\hline ANUGIA & GEGDED & MOCKAR & RAHNOF & XAHQAA \\
\hline ANUGOG & HABQUY & MOCKEV & REWNEO & XALXUF \\
\hline BAZFUF & HANWAW & MOYYEF & REWNEO01 & XALXUFO1 \\
\hline BAZGAM & HEXVEM & MOYYIJ & RICBEM & XITYOP \\
\hline BAZGEQ & HOGLEV & MUDTEL & RUVKAV & XOPLOE \\
\hline BEXVEH & HOGLEV01 & NAYZOE & SEMNEF & YEKXOD \\
\hline CAJOEL & KIJRUS & NIBHOW & SUJNUH & YUGLES \\
\hline CAJQIP & KOJYEO & NIBJAK & SUKYIH & ZIKJIO \\
\hline CAYQUQ & KOJZIT & NIGDIS & SUKYON & ZIKJOU \\
\hline CECVAI & LASDEQ & NUTQAV & SUNLET & \\
\hline CUYWUP & LASYOU & NUTQEZ & TEMPEI & \\
\hline DAKVUI & LAZXOB & OGEBAF & TOHSAL & \\
\hline DAWMUL & LEDLEN & ONIXOZ & VUJBIM & \\
\hline DICKEH & LEHXUT & OWIZAW & XAFFOB & \\
\hline EPISOM & LELDUD & PALTON & XAFFUH & \\
\hline
\end{tabular}


Table S15. Summary of the 18 top performing di-copper OMS containing MOFs identified from the screening analysis for propane/ propylene separation. The structures have been arranged based on their propylene/ propane selectivity for 10/90 mixtures. Further details are available in the CoRE MOF database. ${ }^{13}$

\begin{tabular}{|c|c|c|c|c|c|c|c|}
\hline \multirow[b]{2}{*}{ Index } & \multirow[b]{2}{*}{ REFCODE } & \multirow[b]{2}{*}{$\begin{array}{l}\text { Common } \\
\text { Name }\end{array}$} & \multirow{2}{*}{$\begin{array}{l}10 / 90 \mathrm{n} \\
\text { Volumetric } \\
\text { capacity } \\
(\mathrm{mg} / \mathrm{cc})\end{array}$} & \multicolumn{3}{|c|}{ 50/50 mixtures } & \multirow[b]{2}{*}{ Reference } \\
\hline & & & & Selectivity & $\begin{array}{c}\text { Volumetric } \\
\text { capacity } \\
\text { (mg/cc) }\end{array}$ & Selectivity & \\
\hline 1 & FIQCEN & HKUST-1 & 193.5 & 10.1 & 271.4 & 2.7 & $\frac{10.1126 / \text { science. }}{\underline{283.5405 .1148}}$ \\
\hline 2 & LAZXOB & Cu-EBTC & 148.7 & 8.7 & 223.1 & 2.7 & $10.1021 / \mathrm{cg} 300518 \mathrm{k}$ \\
\hline 3 & MOYYEF & - & 130.3 & 8.3 & 201.5 & 2.6 & $10.1021 / \operatorname{cg} 801026 y$ \\
\hline 4 & NUTQEZ & PCN-16 & 157.0 & 6.2 & 263.7 & 2.1 & $10.1039 / \mathrm{b} 920995 \mathrm{f}$ \\
\hline 5 & XOPLOE & - & 115.2 & 6.2 & 196.8 & 2.2 & $\underline{10.1039 / \mathrm{b} 813226 \mathrm{~g}}$ \\
\hline 6 & MOCKAR & - & 153.3 & 6.2 & 258.6 & 2.0 & $10.1021 / \mathrm{cm} 800403 \mathrm{~d}$ \\
\hline 7 & BEXVEH & - & 150.1 & 6.2 & 255.1 & 2.0 & 10.1039/C3CE27006H \\
\hline 8 & NUTQAV & PCN-16' & 148.0 & 6.1 & 249.1 & 2.0 & $\underline{10.1039 / b 920995 f}$ \\
\hline 9 & MAFJIO & - & 145.8 & 6.0 & 246.3 & 2.0 & - \\
\hline 10 & PARNON & - & 116.9 & 6.0 & 205.3 & 2.4 & - \\
\hline 11 & HOGLEV & - & 166.5 & 5.9 & 292.3 & 2.1 & 10.1002/anie. 200802087 \\
\hline 12 & XITYOP & - & 135.1 & 5.8 & 239.2 & 2.1 & $\underline{10.1021 / j a 0771639}$ \\
\hline 13 & LASDEQ & - & 149.1 & 5.7 & 256.3 & 2.0 & $10.1039 / \mathrm{c} 2 \mathrm{ce} 06384 \mathrm{k}$ \\
\hline 14 & LASYOU & MOF-505 & 134.7 & 5.6 & 240.1 & 2.0 & 10.1002/anie.200462787 \\
\hline 15 & HANWAW & - & 119.3 & 5.3 & 225.9 & 2.1 & 10.1002/chem.201103927 \\
\hline 16 & YEKXOD & - & 101.0 & 5.2 & 190.1 & 2.1 & $\underline{10.1039 / c 2 c c 35340 g}$ \\
\hline 17 & ONIXOZ & USTA-20 & 117.2 & 5.2 & 244.9 & 3.0 & 10.1002/anie. 201007583 \\
\hline 18 & FECXES & - & 128.2 & 5.1 & 261.7 & 2.6 & 10.1039/c2jm15538a \\
\hline
\end{tabular}




\section{Comparison of IAST with binary GCMC calculations}
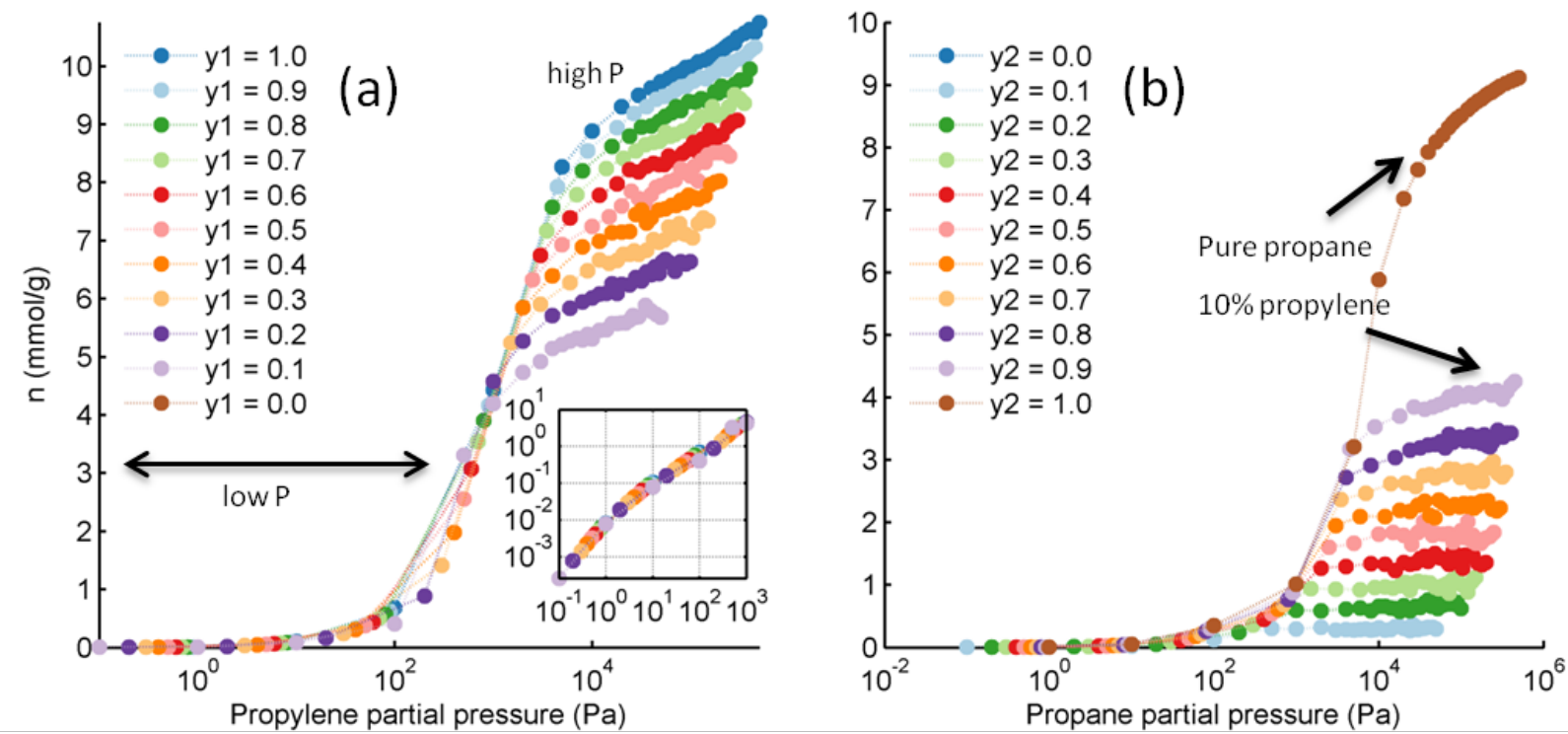

Figure S18. Binary adsorption isotherms for propylene/ propane mixtures calculated using GCMC simulations with the VDW-DF2 (Iteration 2) FF at $303 \mathrm{~K}$ for (a) propylene and (b) propane. Notation: $\mathrm{y}_{1}$ and $\mathrm{y}_{2}$ refer to the gas phase composition of propylene and propane respectively. 


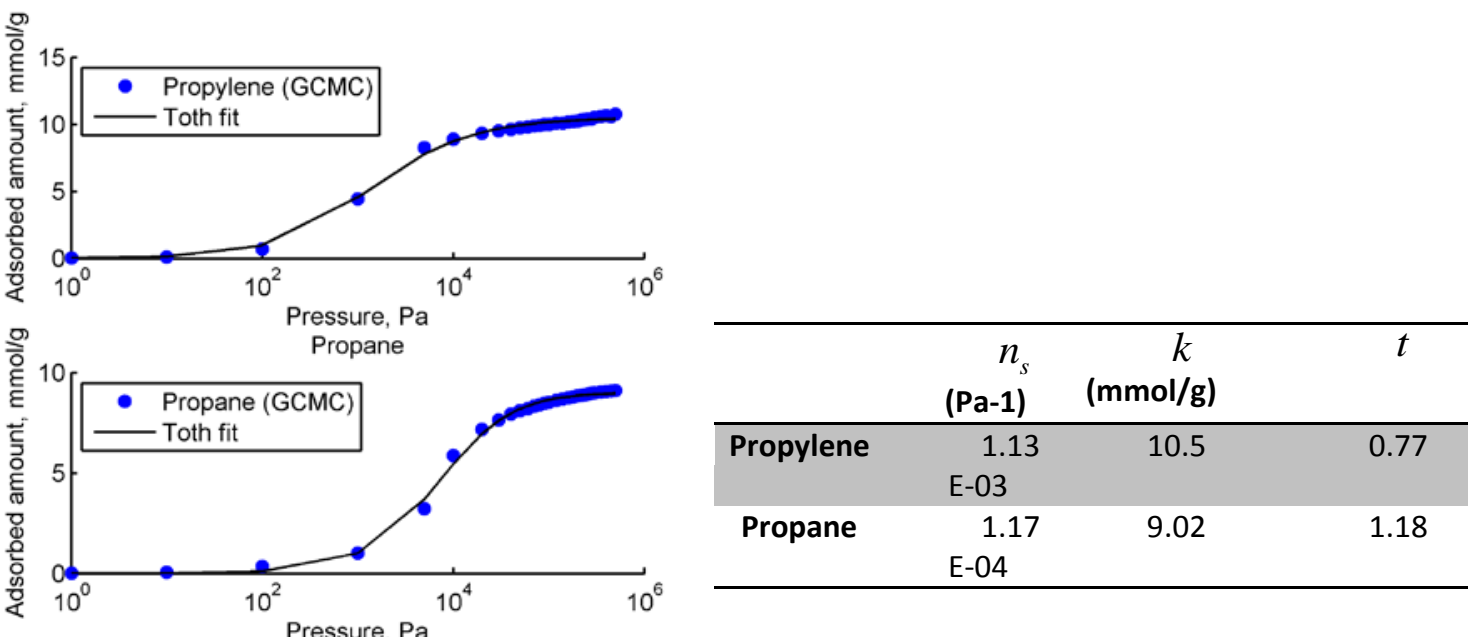

Figure S19. Fitting results and fitting parameters for the pure component propylene and propane adsorption isotherms using the single-site Toth model.

The Toth model used is given by $n=\frac{n_{s} k P}{\left[1+(k P)^{\mathrm{t}}\right]^{1 / t}}$
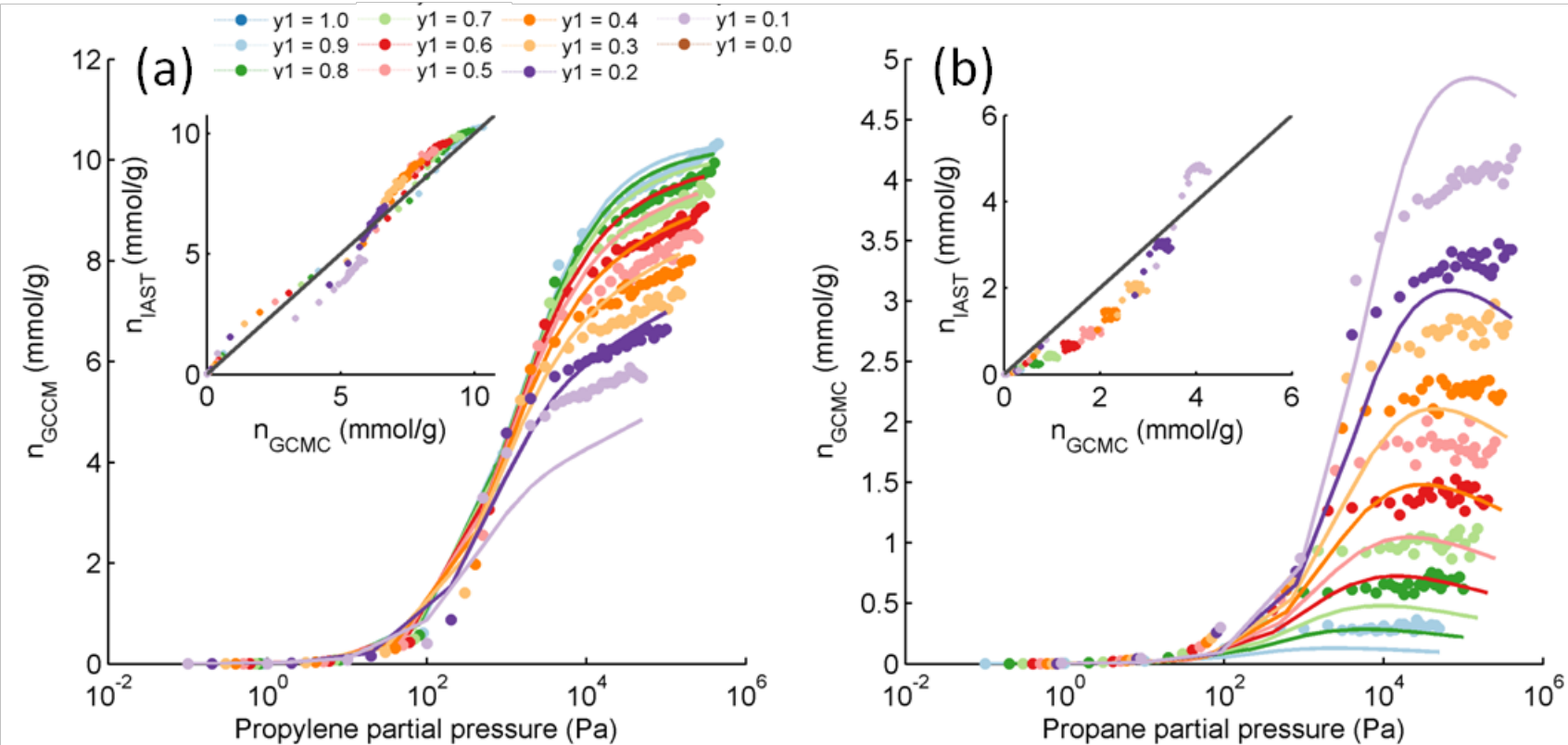

Figure S20. Binary adsorption isotherms for propylene/ propane mixtures calculated using GCMC simulations (solid circles) compared with the IAST predictions (solid lines) Notation: $\mathrm{y}_{1}$ and $y_{2}$ refer to the gas phase composition of (a) propylene and (b) propane respectively. 


\section{REFERENCES}

1. Chui, S. S.-Y.; Lo, S. M.-F.; Charmant, J. P. H.; Orpen, A. G.; Williams, I. D., A Chemically Functionalizable Nanoporous Material [Cu3(TMA)2(H2O)3]N. Science 1999, 283, 1148-1150.

2. Mayo, S. L.; Olafson, B. D.; Goddard, W. A., Dreiding - a Generic Force-Field for Molecular Simulations. J. Phys. Chem. 1990, 94, 8897-8909.

3. Martin, M. G.; Siepmann, J. I., Transferable Potentials for Phase Equilibria. 1. UnitedAtom Description of n-Alkanes. J. Phys. Chem. B 1998, 102, 2569-2577.

4. Dubbeldam, D.; Calero, S.; Vlugt, T. J. H.; Krishna, R.; Maesen, T. L. M.; Smit, B., United Atom Force Field for Alkanes in Nanoporous Materials. J. Phys. Chem. B 2004, 108, 12301-12313.

5. Wang, S.; Yang, Q.; Zhong, C., Adsorption and Separation of Binary Mixtures in a Metal-Organic Framework Cu-BTC: A Computational Study. Sep. Purif. Technol. 2008, 60, 3035.

6. Jorge, M.; Fischer, M.; Gomes, J. R. B.; Siquet, C.; Santos, J. C.; Rodrigues, A. E., Accurate Model for Predicting Adsorption of Olefins and Paraffins on Mofs with Open Metal Sites. Ind. Eng. Chem. Res. 2014, 53, 15475-15478.

7. Kulkarni, A. R.; Sholl, D. S., DFT-Derived Force Fields for Modeling Hydrocarbon Adsorption in MIL-47(V). Langmuir 2015, 31, 8453-8468.

8. $\quad$ Rubes, M.; Wiersum, A. D.; Llewellyn, P. L.; Grajciar, L.; Bludsky, O.; Nachtigall, P., Adsorption of Propane and Propylene on Cubtc Metal-Organic Framework: Combined Theoretical and Experimental Investigation. J. Phys. Chem. C 2013, 117, 11159-11167.

9. He, Y.; Krishna, R.; Chen, B., Metal-Organic Frameworks with Potential for EnergyEfficient Adsorptive Separation of Light Hydrocarbons. Energy Environ. Sci. 2012, 5, 91079120.

10. Fischer, M.; Gomes, J. R. B.; Froeba, M.; Jorge, M., Modeling Adsorption in MetalOrganic Frameworks with Open Metal Sites: Propane/Propylene Separations. Langmuir 2012, 28, 8537-8549.

11. Fischer, M.; Gomes, J. R. B.; Jorge, M., Computational Approaches to Study Adsorption in Mofs with Unsaturated Metal Sites. Mol. Simul. 2014, 40, 537-556.

12. Jorge, M.; Lamia, N.; Rodrigues, A. E., Molecular Simulation of Propane/Propylene Separation on the Metal-Organic Framework Cubtc. Colloids Surf. A 2010, 357, 27-34.

13. Chung, Y. G.; Camp, J.; Haranczyk, M.; Sikora, B. J.; Bury, W.; Krungleviciute, V.; Yildirim, T.; Farha, O. K.; Sholl, D. S.; Snurr, R. Q., Computation-Ready, Experimental MetalOrganic Frameworks: A Tool to Enable High-Throughput Screening of Nanoporous Crystals. Chem. Mater. 2014, 26, 6185-6192. 


\section{Input files for RASPA}

Ethylene

\# critical constants: Temperature [T], Pressure [Pa], and Acentric factor [-]

282.35

5041800.0

0.0866

\# Number Of Atoms

2

\# Number Of Groups

1

\# Alkane-group

flexible

\# number of atoms

2

\# atomic positions

0 CH2_sp2

1 CH2_sp2

\# Chiral centers Bond BondDipoles Bend UrayBradley InvBend Torsion Imp. Torsion Bond/Bond Stretch/Bend Bend/Bend Stretch/Torsion Bend/Torsion IntraVDW IntraCoulomb
$\begin{array}{ll}0 & 1\end{array}$
$\begin{array}{ll}0 & 0\end{array}$
$\begin{array}{lll}0 & 0 & 0\end{array}$
0

\# Bond stretch: atom n1-n2, type, parameters

01 FIXED_BOND 1.33

\# Number of config moves

0

\section{Propylene}

\# critical constants: Temperature [T], Pressure [Pa], and Acentric factor [-]

364.9

4610000

0.144

\# Number Of Atoms

3

\# Number Of Groups

1

\# Alkane-group

flexible

\# number of atoms

3

\# atomic positions

0 CH2_sp2

1 CH_sp2

2 CH3_sp3

\# Chiral centers Bond BondDipoles Bend UrayBradley InvBend Torsion Imp. Torsion Bond/Bond Stretch/Bend Bend/Bend Stretch/Torsion Bend/Torsion IntraVDW IntraCoulomb
02
$0 \quad 1$
$\begin{array}{lll}0 & 0 & 0\end{array}$
0

\# Bond stretch: atom n1-n2, type, parameters

01 FIXED_BOND 1.33

12 FIXED_BOND 1.54

\# Bond bending: atom n1-n2-n3, type, parameters

012 HARMONIC_BEND 70420119.7

\# Number of config moves

0 
force_field_mixing_rules.def

\# general rule for shifted vs truncated

truncated

\# general rule tailcorrections

yes

\# number of defined interactions

19

\# type interaction, parameters. IMPORTANT: define shortest matches first, so that more specific ones overwrites these

$\mathrm{H}$ lennard-jones 7.648985298

C lennard-jones 47.85648039

$\mathrm{N}$ lennard-jones 38.94943833 .262560196

O lennard-jones 48.15841402

P lennard-jones 161.03126943.69722968

S lennard-jones 173.10861463.590321834

I lennard-jones 256.64358573 .69722968

Cl lennard-jones 142.5629957

3.519317206

$\mathrm{Cu}$ lennard-jones 2.518

3.114

CH3_sp3 lennard-jones 98.03 .75

CH2_sp3 lennard-jones 46.03 .95

CH_sp3 lennard-jones 10.04 .65

CH2_sp2 lennard-jones 85.03 .675

CH_sp2 lennard-jones 47.03 .73

C_sp2 lennard-jones 20.03 .85

He lennard-jones $10.9 \quad 2.64$

N_probe lennard-jones 1.01 .84

N_n2 lennard-jones $36.0 \quad 3.31$

N_com none

\# general mixing rule for Lennard-Jones

Lorentz-Berthelot

pseudo_atoms.def

\#number of pseudo atoms

11

\#type print as chem oxidation mass charge polarization B-factor radii connectivity anisotropic anisotropic-type tinker-type

\begin{tabular}{|c|c|c|c|c|c|c|c|}
\hline CH3_sp3 yes & C & $\mathrm{C}$ & - & 15.03450 .0 & 0.0 & 1.0 & 1.0 \\
\hline CH2_sp3 yes & $\mathrm{C}$ & $\mathrm{C}$ & 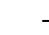 & 14.02650 .0 & 0.0 & 1.0 & 1.0 \\
\hline CH_sp3 yes & $\mathrm{C}$ & $\mathrm{C}$ & - & 13.01860 .0 & 0.0 & 1.0 & 1.0 \\
\hline CH2_sp2 yes & $\mathrm{C}$ & $\mathrm{C}$ & - & 14.02650 .0 & 0.0 & 1.0 & 1.0 \\
\hline CH_sp2 yes & $\mathrm{C}$ & $\mathrm{C}$ & - & 13.01860 .0 & 0.0 & 1.0 & 1.0 \\
\hline C_sp2 yes & $\mathrm{C}$ & $\mathrm{C}$ & - & $\begin{array}{ll}12.0107 & 0.0\end{array}$ & 0.0 & 1.0 & 1.0 \\
\hline $\mathrm{Cu}$ yes & $\mathrm{Cu}$ & $\mathrm{Cu}$ & - & $63.546 \quad 0.0$ & 0.0 & 1.0 & 1.0 \\
\hline He yes & $\mathrm{He}$ & $\mathrm{He} \quad-$ & & \multicolumn{2}{|c|}{$\begin{array}{lll}4.002602 & 0.0 & 0.0\end{array}$} & 1.0 & $1.0 \quad 0$ \\
\hline N_probe $\quad y$ & res & $\mathrm{N} \quad \mathrm{N}$ & - & \multicolumn{2}{|c|}{$\begin{array}{lll}14.00674 & 0.0 & 0.0\end{array}$} & 1.0 & $1.0 \quad 0$ \\
\hline N_n2 yes & $\mathrm{N}$ & $\mathrm{N}$ & & $14.00674 \quad-0.482$ & 0.0 & 1.0 & $0.7 \quad 0$ \\
\hline N_com & & $\mathrm{N}$ & - & $\begin{array}{lll}0.0 & 0.964 & 0 .\end{array}$ & .0 & 1.0 & $0.7 \quad 0$ \\
\hline
\end{tabular}
2.846421404 3.472723203

033153776 